\title{
Sobre la ambivalencia categorial de un montón y otros cuantificadores afines
}

\section{Planteamientos y objetivos}

Dado el potencial que exhiben para la expresión de una cantidad indefinida (superlativa), unidades como montón, barbaridad, burrada o porrón han sido incluidas entre los sustantivos cuantificadores (Martínez, 1999, 2013; Vos, 2002; Saab, 2006; Gutiérrez Rodríguez, 2008; NGLE; Verveckken, 2015). En efecto, algunas de sus propiedades de relación sintagmática resultan típicamente sustantivas $(\$ 3)$; pero, por otro lado, también pueden intervenir en la oración desempeñando funciones sintácticas adverbiales $(\$ 4)$.

En las líneas que siguen, nos proponemos proporcionar una explicación a este - ya anunciamos que aparente- hibridismo categorial. Nos servimos para ello de los principios teórico-metodológicos de la Gramática Funcional del Español ( $c f$. San Julián Solana, 2014: 18-23).

\section{Cuantificadores propios vs. cuantificadores eventuales}

2.1. Las propiedades cuantitativas de los sustantivos docena, millar o mayoría residen en sus figuras de contenido léxico. Les son, pues, connaturales, sin que esto sea óbice para que, por efecto de la información proveniente del entorno textual o extratextual, puedan adquirir sentidos ${ }^{1}$ que se apartan en mayor o menor medida de su genuina significación (v.g., el cardinal léxico millón suele

1 Se emplea el término sentido para hacer referencia al contenido que globalmente se transmite con un mensaje, y que es el resultado de la congruencia entre: $a$ ) el significado o significación, y $b$ ) los datos derivados del contexto, la situación o el universo del discurso (información circunstancial) ( $c f$. San Julián Solana, 2016b: $\$$ 4.2.2). 
usarse contextualmente como cuantificador evaluativo en enunciados del tipo de $i$ Te lo be dicho un millón de veces!).

2.2. Bien distinta es la situación que a este respecto ofrecen sustantivos como enjambre, manada, saco o avalancha. Aunque los cuatro conocen en los actuales usos del español empleos como cuantificadores evaluativos en función de los cuales pasan a expresar 'gran cantidad' (ejs. 1), todos ellos comparten la característica de ser unidades léxicamente designativas ${ }^{2}$, faceta esta que exhiben en los ejs. de (2):

1) a. Desde la distancia, divisó un enjambre de niños disfrazados;

b. Una manada de adolescentes se \{apoderó/apoderaron\} del parque;

c. Llegó a la tutoría con un saco de dudas;

d. Se vio sorprendido por una avalancha de solicitudes;

2) a. Desde la distancia, divisó un enjambre de abejas africanas;

b. Una manada de perros callejeros se \{́apoderó/apoderaron\} del parque;

c. Llegó a la tutoría con un saco de libros y una bolsa de revistas;

d. Se vio sorprendido por una avalancha de lodo.

Así pues, su ocasional desempeño como cuantificadores constituye una propiedad adquirida en las particulares circunstancias en que tiene lugar el acto comunicativo. Obsérvese, sin ir más lejos, cómo la supresión de los complementos determinativos que en los ejs. de (1) se subordinan, respectivamente, a enjambre, manada, saco y avalancha se salda con la inmediata volatilización del sentido cuantitativo y con la recuperación de su original valor designativo:

3) a. Desde la distancia, divisó un enjambre.

b. Una manada se \{apoderó/*apoderaron\} del parque;

c. Llegó a la tutoría con un saco;

d. Se vio sorprendido por una avalancha.

$\mathrm{Y}$ es que, de su asociación con tales complementos, surgen secuencias «desviadas», en la medida en que atentan contra las pautas de selección léxica sancionadas por los usos sociales de la lengua; para que adquieran pleno sentido,

2 De acuerdo con sus rasgos pertinentes de contenido, ciertos signos designan una clase de realidades que satisfacen las propiedades definidas por tales rasgos, sin hacer por ello alusión a ninguno de sus componentes en particular. Solo al quedar debidamente «actualizados» en un acto de habla concreto, algunos de ellos pasan a denotar ejemplares de la clase designada ( $c f$. Gutiérrez Ordóñez, 1989: \$ 4). Frente a las unidades designativas, las determinativas - entre las que se encuentran los cuantificadores - son poseedoras de un contenido cuyos rasgos pertinentes especifican la aplicación referencial (directa o indirecta) de otro signo (San Julián Solana, 2016a: \$ 3.2.1, 3.3). 
tales expresiones han de ser «reducidas» a formulaciones acordes con los usos vigentes mediante la «metasemia» o cambio de significado de uno de sus términos (Martínez, 1975). En otras palabras, el valor cuantitativo de las secuencias destacadas en (1) viene dado por vía metafórica.

2.3. A los cuantificadores del primer tipo (\$ 2.1) los llamamos cuantificadores propios o léxicos, mientras que reservamos la denominación de cuantificadores eventuales para los segundos ( $\$ 2.2)$, dada su connatural carácter designativo.

2.4. En principio, parece que secuencias como un montón, una barbaridad ( burrada bestialidad) o un porrón no supondrían casos distintos a los de un enjambre, una manada, un saco, una avalancha o un aluvión, ya que estarían nucleadas por sustantivos léxicamente designativos que, no obstante, suelen adquirir en el decurso un sentido cuantitativo vinculado a la expresión de una 'gran cantidad'. Sin embargo, su comportamiento no es por entero coincidente, ya que los de la primera serie, además de exhibir un comportamiento típicamente sustantivo $(\$ 3)$, entran en funciones reservadas a las unidades adverbiales $(\$ 4)$.

\section{Rasgos sustantivos de un montón, una barbaridad, un porrón...}

3.1. En contra de la hipótesis de que forman locución con $u n / a$, se alzan, en principio, las muestras en las que toman otro actualizador, sin renunciar por ello al sentido de 'gran cantidad'3:

4) [...] ya estaba escuchando su montón de majaderías [CE]; Aunque radio Voz sea un grupo local, es una vergüenza que le den este porrón de frecuencias para que luego las realquilen a otros [CE]; Tendremos que esperar otro porrón de años para volver a verlo; [...] ruego que alguien demuestre que el Sr.García Cabreros cobró tal barbaridad de dietas [CE]; Por cierto, felicidades por $t u$ barbaridad de visitas [CE].

3.2. También cuentan con la posibilidad de llevar adyacentes adjetivos:

5) Ya hemos visto un buen montón de trucos para ir eliminando estos restos $[C E] ;[. .$.$] en aquel disco había un buen porrón de versiones geniales [CE];$ [...] ganan una tremenda barbaridad de dinero gracias a la comida [CE]; Después de una preocupante barbaridad de tiempo me he leído al fin la

3 Su general rechazo a los cuantificadores (Vos, 2002: 49) se debe a que estos resultan incompatibles con el sentido cuantitativamente evaluativo; antes bien, fuerzan la interpretación designativa, cuando el contexto la tolera: En el bospital le bicieron \{un/ otro/*medio\} montón de pruebas; Todavía conserva (\#dos) montones de vinilos. 
última adaptación de Junko Mizuno [CE]; Muchísimas bombas han caído sin explotar, una verdadera burrada de ellas [CE].

3.3. Gozan, además, de variación morfológica, como pone de manifiesto su capacidad para tomar el morfema de 'plural', sin que esto conlleve la desaparición del valor cuantitativo:

6) Hay montones de lugares que no podemos visitar tranquilos por lo peligrosos que son [CE]; Se gasta porrones de euros en tonterías [oral]; Eso de que los internautas son millonarios y que facturan barbaridades de dinero solo se lo creen mentes inocentes como la suya [CE]; Nos hemos gastado burradas de dinero en cubrir grandes extensiones de terreno $[\mathrm{CE}]^{4}$.

\section{Rasgos adverbiales de un montón, una barbaridad, un porrón...}

4.1. Estos cuantificadores, a diferencia de los que veíamos en (1), pueden cuantificar al verbo desde la función adverbial de complemento circunstancial:

7) Los toros le gustan un montón; Juan sale de fiesta un porrón; Héctor hizo el ganso una barbaridad; En aquella época, movíamos el coche una burrada, no que ahora.

Pero esto no garantiza que nos hallemos ante auténticas locuciones adverbiales. Ha de tenerse presente que el adjetivo uno/a/os/as, en claro contraste con el artículo (el/la/los/las/lo), disfruta de estatus de sintagma: es susceptible, en asociación con un signo entonativo, de constituir autónomamente - y al margen de casos de mención - un enunciado (Alarcos, 1970: caps. XIII, XVII; Álvarez Martínez, 1986). Esto abre la posibilidad de que las secuencias destacadas en (7) sean grupos sintagmáticos internamente trabados por solidaridad glosemática y, en consecuencia, «exocéntricos». Ciertamente, la función de solidaridad o interdependencia entraña una suerte de transposición, en el sentido de que los grupos que se articulan sobre su base adquieren una categoría gramatical distinta a la de sus sintagmas componentes (Martínez, 1994a: \$ 4.2.4; 1994b: $\$ 1.3 \cdot 3$ ).

4 Asimismo, son compatibles con derivativos encarecedores de la cantidad: Tiene un \{montonazo/porronazo\} de juegos; Piden una megabarbaridad de puntos; Tiene una burradota de personajes; pero este rasgo no es diferenciador de las categorías consideradas (la sustantiva y la adverbial), ya que también los toleran algunos adverbios (incluso «propios»): lejitos, cerquita, ultralejos, supercerca. De hecho, adelantamos ya que sufijados - más dudoso es que lo hagan con prefijo- pueden intervenir en las funciones de complemento circunstancial y término terciario $(\$ 4)$. 
Precisamente por formar grupo solidario con esta unidad determinativa, los sustantivos bora, temporada, paso y calles pueden intervenir como complemento circunstancial en las siguientes oraciones ( $c f$. Martínez, 1994b: cap. III):

8) Juan salió de fiesta una bora (*Juan salió de fiesta hora / *Juan salió de fiesta una); Héctor hizo el ganso una temporada, pero luego ya se centró (*Héctor hizo el ganso temporada / *Héctor hizo el ganso una); Lo movimos un palmo (*Lo movimos palmo / *Lo movimos uno); Me acompañó unas calles (*Me acompañó calles / *Me acompañó unas).

No habría que descartar, por ende, que las secuencias destacadas en (7) representaran casos equivalentes.

4.2. Sin embargo, no debe pasarse por alto que tales segmentos también intervienen como inequívocos términos terciarios (de adjetivos o adverbios)

9) a. [...] iba a tener una casa un montón de bonita ${ }^{6}$; Te lo dije una vez, eres un porrón de bueno y no te quiero cambiar por nada ${ }^{7}$; Me vino con un regalo una barbaridad de caro;

b. La verdad es que me has encontrado un montón de bien [CE]; Estoy una barbaridad de lejos de Aberowen ${ }^{8}$; Pues me pilla un porrón de lejos ${ }^{9}$;

y, a pesar de que es cierto que los sustantivos también pueden tomar parte de la función de término terciario si lo hacen formando grupo sintagmático solidario, lo es igualmente el hecho de que entonces han de subordinarse a una unidad que conlleve el valor de 'comparación' (Martínez, 1994c: \$ 3.2.4):

5 En el paradigma funcionalista, la de «término terciario» (Martínez, 1994c: cap. III) es una construcción sintáctica suboracional que responde a las siguientes características: a) es categorialmente adverbial - para que los sustantivos tengan cabida, han de hacerlo subordinados a un adjetivo o adverbio portador del valor de 'comparación' y en las mismas condiciones que precisan para su funcionamiento como complemento circunstancial (Martínez, 1994b: cap. III)—; b) se trata, en principio, de un adyacente subordinado a un núcleo funcionalmente adjetivo o adverbial, si bien el propio Martínez (1994c: $\$$ 3.2.4) habla de la posibilidad de que el funtivo constante sea un sustantivo o incluso el conjunto de la oración; $c$ ) ocupa una posición prenuclear; d) está desempeñada por unidades morfológicamente neutras y que, por tanto, no se ven afectadas por la concordancia; $e$ ) da lugar a una construcción permanentemente asociada con la significación de 'cuantificación indefinida'. Cf. también Fernández Lorences (2004).

6 M. E. Cardenal de la Nuez: El paso a la vida adulta. Dilemas y estrategias ante el empleo flexible. Madrid: CIS, 2006, 205.

7 http://www.fotolog.com/shek_asm/40127432/(13-1-2015).

$8 \quad$ K. Follett: La caída de los gigantes. Barcelona: Plaza \& Janés, 2010, 761.

9 Foro Brompton: «Busco bolsa T-bag»: http://www.forobrompton.es/foro//viewtopic. php? $\mathrm{f}=14 \& \mathrm{t}=2244(16-10-2015)$. 
10) Juan es una bora más joven que su primo (*Juan es una hora joven); María y Sonia son un año mayores que Juan (*María y Sonia son un año grandes); Ella es un palmo más alta que él (*Ella es un palmo alta); Arturo tiene el coche unas calles más cerca (*Lo tiene unas calles cerca).

\section{Propuesta de explicación: dobletes en sincronía}

5.1. El comportamiento adverbial de lo que en principio parecen sustantivos no ha pasado del todo desapercibido a algunos autores. La $N G L E(\$ 12.5 \mathrm{e})$ y Verveckken (2015), por ejemplo, conciben (un) montón como un sustantivo cuantificativo, si bien admiten que en el español de hoy cuenta con la peculiaridad de admitir usos adverbiales. Pero ¿cómo es posible que un mismo signo funcione a dos bandas?

5.2. Gómez Torrego (2001, 2005), por su parte, estima que un montón de, una burrada de, una barbaridad de y un porrón de son en realidad locuciones adverbiales. Claro está, su postura choca frontalmente con los rasgos destacados en $\$$ 3. Pero, además, la idea de que la forma de la preposición de está fraseológicamente incorporada encuentra muy difícil encaje con dos hechos: en los casos de elipsis del sustantivo cuantificado, la ausencia de la preposición no acarrea la ruina del valor cuantitativo: Un montón llegaron tarde. Y aunque entonces podría aducirse que la preposición también está elidida, no puede argüirse lo mismo cuando lo cuantificado es el verbo: Estudia inglés un montón.

5.3. Desde la perspectiva teórica adoptada, la única solución viable pasa por el reconocimiento de parejas de signos distintos, aunque de significante parcialmente coincidente. En este orden de cosas, con los sustantivos montón/es, barbaridad/es, burrada/s, porrón/es, convivirían los signos mínimos de categoría adverbial (locuciones) un montón, una barbaridad, una burrada y un porrón.

Serían los de esta última serie - en cuanto adverbios propia y puramente cuantitativos - los únicos que entrarían (al margen de la mediación del valor de (comparación') en la función de término terciario. No es casual que, precisamente en tal contexto sintáctico, la expresión /uN/ o /una/ ya no resulte separadamente conmutable por la de otro actualizador, al tiempo que los aparentes sustantivos dejan de admitir adyacentes adjetivales y variación morfológica:

11) Iba a tener una casa un montón de bonita (*su montón de bonita / *un enorme montón de bonita / *montones de bonita); Eres un porrón de bueno (*tu porrón de bueno / *un grandísimo porrón de bueno / *porrones 
de bueno); Estoy una barbaridad de lejos (*mi barbaridad de lejos / *una enorme barbaridad de lejos / *barbaridades de lejos); Me vino con un regalo una burrada de caro (*esta burrada de caro / *una impresionante burrada de caro / *burradas de caro).

Es muy probable que en el marco de la función de complemento circunstancial también se den cita las unidades adverbiales obtenidas por lexicalización, y ello a pesar de que, en términos generales, dicha construcción sintáctica admite la participación de sustantivos formando grupo sintagmático - eventualmente reducido a uno de sus funtivos componentes- (Martínez, 1994b: cap. III):

12) Juan practica esgrima un montón (*su montón / *un tremendo montón / montones ${ }^{10}$ ); Sus compañeros la golpearon un porrón (*su porrón / *un gran porrón / ??porrones); Héctor hizo el ganso una barbaridad (*esta barbaridad / *una tremenda barbaridad / *barbaridades); Entonces usábamos la bici una burrada (*aquella burrada / *una impresionante burrada /*burradas).

Donde sí alternarían las estructuras de complemento determinativo nucleadas por los sustantivos (designativos) montón/es, barbaridad/es, burrada/s y porrón/ es, y las construcciones de término terciario - en las que el segmento lexicalizado entraría como funtivo subordinado o variable - sería en los casos de cuantificación de sustantivos.

5.4. La diferencia entre los sustantivos designativos y los correspondientes adverbios léxicamente cuantitativos con significante «clónico» se revela mucho más clara cuando la unidad morfológicamente neutra adopta la forma del sustantivo escueto: cantidad/es (sust.) y cantidad (adv.), multitud/es y multitud,

10 Aunque hemos llegado a documentarlo, el empleo de montones como cuantificador del verbo desde la función de complemento circunstancial es francamente muy restringido si se compara con el de un montón. A este respecto, conviene no olvidar que algunos grupos sintagmáticos formados por sustantivos emparejados pueden verse reducidos en el plano de expresión a uno de sus sintagmas componentes - si se trata de un sustantivo contable, deberá presentarse necesariamente en plural- (Martínez, 1994b: \$ 3.4.3.3): Se pasó tocando la flauta boras (y horas)... Que montones no ha terminado instituyéndose en un adverbio cuantitativo (inmovilizado bajo la forma de plural e indefinición) se revela en el hecho de que no es capaz de caracterizar a adjetivos y adverbios (ejs. 11), y no precisamente por incompatibilidad semántica - como le sucede a multitud, que incorpora el rasgo léxico de 'pluralidad'-, puesto que no ofrece resistencia alguna a recibir como complemento cuantitativo a sustantivos medibles; además, aun pluralizado conserva la propiedad de ser término de concordancia: «[...] según dijo, "se van a perder montones de dinero"» (El País, 21-5-1997). Concluyendo, creemos que el valor cuantitativo de montones sigue siendo de base contextual, a pesar de su alto grado de consolidación en los usos de la lengua. 
mogollón/es y mogollón, mazo/s y mazo... No en vano, los sustantivos comunes contables en singular necesitan ir actualizados para ser sujetos antepuestos -incluso si se presentan formando un grupo sintagmático no concebible como plural sintáctico- (ejs. 13); así pues, la gramaticalidad de las muestras de (14) ha de interpretarse como el testimonio de que los cuantificadores que las encabezan no son término nuclear dentro del grupo sustantivo en función de sujeto léxico, sino funtivo variable (de hecho, ellos mismos actualizan al sustantivo cuantificado):

13) *Taza se ha caído al suelo; *Bolsa de libros está rota; *Perro de presa mordió al niño;

14) Cantidad de indicios lo señalan como culpable; Multitud de gatos han sido adoptados en los últimos días; Mogollón (de ordenadores) tienen el dichoso virus $^{11}$.

La oposición entre sustantivos designativos y adverbios cuantitativos parcialmente homófonos también se torna más fácilmente perceptible cuando la unidad inmovilizada incorpora fraseológicamente la forma del artículo: tira/s (sust.) y la tira (adv.), leche/s y la leche, mar/es y la mar, hostia/s y la bostia... En primer lugar, la forma $/ \mathrm{la} /$ no resulta separadamente conmutable por la de otro actualizador, lo que pone de manifiesto que entonces no debe concebirse como el significante del artículo femenino singular, sino como parte integrante del significante de un signo mínimo (ejs. 15). Precisamente por ello, dicha secuencia fonológica no lleva solidariamente asociado contenido alguno, incluida la marca de 'identificabilidad'. Es la ausencia de este rasgo semántico lo que explica que estos cuantificadores puedan participar en la función de complemento directo respecto del verbo baber, que rechaza en dicho rol sintáctico a sustantivos que toman el artículo sin justificación catafórica (ejs. 16). Y, a diferencia de lo que sucede con los cuantificadores del tipo de un montón, su intervención de forma aislada en la función de complemento circunstancial resulta categorialmente inequívoca, ya que - al no gozar el artículo de estatus de sintagma - en ningún momento asoma la duda de que nos encontremos ante grupos sintagmáticos exocéntricos trabados por interdependencia (ejs. 17):

11 Debido a su significado netamente determinativo, los cuantificadores propios presuponen un cuantificado al que aplicarse. Dicha circunstancia explica que estos adverbios, a pesar de su condición de adyacentes, tengan la posibilidad de representar en el plano de expresión a todo el grupo nominal en los casos en los que el sustantivo nuclear se da por consabido; este último, no obstante, ha de recuperarse en el plano de contenido para que el enunciado resulte interpretable (San Julián Solana, 2016b: $\$ 4 \cdot 3 \cdot 4$ ). 
15) Tengo $\left\{1 \mathrm{la} /{ }^{*}\right.$ una $/{ }^{*} \mathrm{mi} /{ }^{*}$ otra $\}$ tira de sueño; Es $\left\{1 \mathrm{la} /{ }^{*}\right.$ una/*esta/*cierta $\}$ mar de interesante;

16) a. *En Madrid hay los teatros;

b. En Madrid hay \{la tira / la leche / la hostia / la mar\} de teatros;

17) Estudia inglés la tira; Riega las plantas la bostia.

\section{6 ¿Transposición o lexicalización?}

6.1. Una vez constatado que bajo el aparente hibridismo categorial de un montón, una barbaridad ( brutalidad bestialidad) y un porrón subyace la coexistencia de signos funcionalmente disímiles - aunque prácticamente homófonos-, cabe plantearse si tales adverbios resultan de una adaptación in actu (sincrónica) o si, por el contrario, se deben a un proceso (diacrónico y, en consecuencia, gradual) de lexicalización.

6.2. Como adaptaciones puntuales -entroncadas, pues, con la transposición ${ }^{12}$ - son presentados por algunos autores:

[...] basta con seleccionar [...] un sustantivo con algún rasgo léxico que favorezca la cuantificación y eliminarle su posibilidad de concordancia, pues con ello de convierte funcionalmente en un adverbio. (Martínez García, 2008: 4-5)

Basta con aplicar algunas de estas unidades [sustantivos según el autor] a un adjetivo o a un adverbio, para pasar a la construcción cuantitativa o gradual del «término terciario». (Martínez, 2013: 318, n. 18)

Ahora bien, el evidente salto que hay entre el significado léxico de los sustantivos considerados (significado de tipo designativo) y el de los correspondientes adverbios de significante «clónico» (determinativo-cuantitativo) choca con la máxima funcionalista de que la adaptación categorial a que da lugar el recurso puramente sintáctico de la transposición no altera el significado de la unidad transpuesta (Martínez, 1994b: $\$ 1.3 .5$ ), frente a lo que sucede en mayor o menor grado con los procesos (diacrónicos) de enriquecimiento del léxico.

12 Sin ir más lejos, el signo dependiente de que media entre el cuantificador y el nominal cuantificado ha llegado a describirse en términos de pre-posición pos-puesta destinada a transponer el «sustantivo» precedente a categoría adverbial (Meilán García, 1990: 646; Martínez García, 2008: 13). 
Aún hay más: el cambio categorial operado por el fenómeno transpositivo tiene efecto en una unidad superior a la transpuesta, pero las subordinaciones iniciales permanecen inalteradas (loc. cit.). Pues bien, en $\$ 4$ tuvimos oportunidad de comprobar que, en cuanto inequívocos adverbios, están privados de capacidad para llevar adyacentes adjetivales.

6.3. Frente a la idea que se desprende de las dos citas anteriores, la formación de las unidades adverbiales cuantitativas que ahora focalizan nuestro interés es más una cuestión de usos consolidados que el resultado de un mecanismo al alcance de la creatividad del hablante, y eso a pesar de que el germen sí se encuentra en actos de habla individuales y «creativos» (i. e., rupturistas con los usos).

Ya sea el resultado de su participación en un grupo nominal desviado interpretable metafóricamente (como sucede con montón), ya se produzca a partir de grupos nominales atributivos (como pasa con barbaridad y sus cuasi sinóni$\operatorname{mos}^{13}$ ), el empleo de un sustantivo designativo como cuantificador constituye, en su origen, un acto innovador ligado a la esfera del «hablar concreto»; en otros términos, la asociación entre el significante de un sustantivo designador y el contenido de índole cuantitativa comienza siendo unicontextual.

Nada impide, sin embargo, que algunas de estas asociaciones alcancen difusión entre los integrantes de una determinada comunidad lingüística, pasando a constituir fenómenos de «norma» $\mathrm{o}$ «uso» social. Es lo que sucede en los ejs. de (1), en los que el vínculo entre la expresión del sustantivo clasificador y el sentido cuantitativo está parcialmente codificado (de ahí que suelan recogerlo los diccionarios), pero aún no está totalmente emancipado del contexto, la situación o el universo del discurso (recuérdese cómo los sustantivos de [1], en ausencia del complemento determinativo que da lugar a la «desviación», se interpretan designativamente).

En ciertos casos, el contenido cuantitativo termina por independizarse del contexto, de suerte que su asociación con una expresión determinada deja de ser ocasional - y fruto de una operación pragmática-, tornándose solidaria y estable. En suma, se consolida como significado de un nuevo signo lingüístico. Inmovilizadas morfológicamente, estas creaciones sígnicas exhiben unas pautas combinatorias que las sitúan en la categoría adverbial.

13 Los usos cuantitativos de barbaridad, burrada, bestialidad y brutalidad parecen surgir sobre la base de grupos del tipo del que se destaca en Formuló una barbaridad de pregunta. Cf. Verveckken, 2015: \$ 5.2.5. 
Atendiendo al cariz gradual del fenómeno, no ha de extrañar que en sincronía estas creaciones léxicas convivan - tal y como sucede en los casos que hemos analizado- con los eventuales empleos cuantitativos de los sustantivos clasificadores de los que se derivan.

6.4. Que la capacidad de las unidades estudiadas para funcionar como adverbios es algo que tiene que ver con la consolidación de usos sociales, y no con un pretendido recurso sincrónico para adverbializar un inventario abierto de sustantivos, se torna patente mediante el cotejo de montón/es y cúmulo/s. A pesar de que la significación (designativa) de ambos sustantivos se asemeja en extremo, solo el primero ha terminado dando lugar a una locución adverbial cuantitativa. Las posibilidades con que cuenta el segundo para cuantificar se restringen, hoy por hoy, a su circunstancial participación en una expresión desviada reductible por metasemia (ej. 19); en cambio, rechaza la función de término terciario (ejs. 20) y parece que aun la de complemento circunstancial (ejs. 21) ${ }^{14}$ :

19) Un (enorme) cúmulo de fatalidades \{ha/han $\}$ provocado su dimisión;

20) *Iba a tener una casa un cúmulo de bonita; ${ }^{*}$ Me has encontrado un cúmulo de bien;

21) *Los toros le gustan un cúmulo; *Practica esgrima un cúmulo.

6.5. Tampoco es casual que, en su faceta de cuantificador (más bien limitada al español europeo), un buevo solo se documente en cuanto adverbio - nótese que nunca acepta adyacentes adjetivos (Al acto acudió un ['gran] buevo de gente) ni es susceptible de pluralización (*El pobre aún tiene buevos de preocupaciones) ${ }^{15}$-. No en vano, su origen no parece encontrarse en grupos nominales con complemento determinativo interpretables cuantitativamente por vía pragmática, sino en la expresión idiomática ponderativa costar ( valer) un buevo 'costar mucho' (lit. 'costar un testículo').

Igualmente, no hay en la actualidad rastro alguno del empleo figurado como cuantificadores de los sustantivos designativos leche/s, hostia/s y virgen/es. En cambio, sí gozan de plena vitalidad las interjecciones que se han originado a

14 La idea de que este rechazo tal vez pudiera deberse a que cúmulo/s incorpora el rasgo semántico de 'pluralidad' se ve deslegitimada por las numerosas muestras en que exhibe su compatibilidad con sustantivos medibles no colectivos.

15 Aunque se trata de un fenómeno marginal, /uN/ sí aparece a veces reemplazado por la forma de otros actualizadores no cuantitativos, lo cual posiblemente se deba al análisis metalingüístico -no necesariamente consciente - al que los hablantes someten algunas locuciones (San Julián Solana, 2015: 695). Con bastante frecuencia sirve de base al sufijo aumentativo -azo, pero este tipo de derivativos no son exclusivos de la categoría sustantiva $\left(\$_{3}\right)$. 
partir de ellos, y que seguramente constituyen el germen de los adverbios la leche, la bostia y la virgen.

\section{Bibliografía}

Alarcos Llorach, E. (1970): Estudios de gramática funcional del español. $3 .^{\mathrm{a}}$ ed. Madrid: Gredos, 1980.

Álvarez Martínez, M. Á. (1986): El artículo como entidad funcional en el español de boy. Madrid: Gredos.

$C E$ = Davies, M. (2002-): Corpus del Español: http://www.corpusdelespanol. org (23-10-2016).

Fernández Lorences, T. (2004): «Eso sí que no se puede negar: la intensificación mediante términos terciarios». Interlingüística, 15/1, 487-496

Gómez Torrego, L. (2001): «Locuciones intensificadoras modernas». Rinconete, 14/2/2001: http://cvc.cer-vantes.es/el_rinconete/(13-1-2015).

Gómez Torrego, L. (2005): «Gramática y semántica de los intensificadores de adjetivos y adverbios». En: Filología y Lingüística. Estudios ofrecidos a Antonio Quilis. Madrid: CSIC, I, 459-479.

Gutiérrez Ordóñez, S. (1989): Introducción a la semántica funcional. Madrid: Síntesis.

Gutiérrez Rodríguez, E. (2008): Rasgos gramaticales de los cuantificadores débiles [tesis doctoral]. Madrid: Universidad Complutense de Madrid: http:// portal.uned.es (16-11-2014).

Martínez, J. A. (1975): Propiedades del lenguaje poético. Oviedo: Universidad de Oviedo.

Martínez, J. A. (1994a): Propuesta de gramática funcional. Madrid: Istmo.

Martínez, J. A. (1994b): Funciones, categorías y transposición. Madrid: Istmo.

Martínez, J. A. (1994c): Cuestiones marginadas de gramática española. Madrid: Istmo.

Martínez, J. A. (1999): «La concordancia en español». En: I. Bosque, V. Demonte (dirs.), Gramática descriptiva de la lengua española. Madrid: Espasa Calpe, II, 2695-2786.

Martínez, J. A. (2013): «Cuantificación y clasificación en los grupos nominales del español». En: D. García Velasco et alii (eds.), A Life in Language. Estudios en homenaje al profesor José Luis García Escribano. Oviedo: Universidad de Oviedo, 301-335. 
Martínez García, H. (2008): «Dos construcciones cuantitativas: partitiva y de término terciario». Círculo de Lingüística Aplicada a la Comunicación, 34, 3-17: http://www.ucm.es/info/circulo/ (25-6-2008).

Meilán García, A. J. (1990): «Algunas cuestiones acerca de la función de sujeto». En: M. Á. Álvarez Martínez (ed.), Actas del Congreso de la Sociedad Española de Lingüística. XX Aniversario (Tenerife, 2-6 de abril de 1990). Madrid: Gredos, II, 639-652.

NGLE = RAE, ASALE (2009): Nueva gramática de la lengua española. Madrid: Espasa.

Saab, A. L. (2006): «Concordancia ad sensum y elipsis nominal en español: un análisis morfosintáctico». Revista de Lengua y Literatura, 34, 45-63.

San Julián Solana, J. (2014): «La impronta del funcionalismo en los estudios lingüísticos del asturiano». Revista de Filoloxía Asturiana, 14, 15-51: http:// www.unioviedo.es/reunido/index.php/RFA/article/view/10897 （2-52016).

San Julián Solana, J. (2015): «Sintaxis, significación y sentido de las ¿locuciones? alrededor de, en torno a y cerca de». En: Studium Grammaticae. Homenaje al profesor José A. Martínez. Oviedo: Universidad de Oviedo, 691-710.

San Julián Solana, J. (2016a): La expresión sustantiva de la cuantificación en español [tesis doctoral]. Oviedo: Universidad de Oviedo.

San Julián Solana, J. (2016b): «El sustantivo cuantificador en la lingüística hispánica: revisión crítica y nueva propuesta». Círculo de Lingüistica Aplicada a la Comunicación, 68, 380-435: https://revistas.ucm.es/index. php/CLAC (1-12-2016).

Verveckken, K. (2015): Binominal Quantifiers in Spanish. Conceptually-Driven Analogy in Diacbrony and Synchrony. Berlin / New York: Walter de Gruyter.

Vos, R. (2002): «Las construcciones de cuantificador nominal en holandés y español». Foro Hispánico, 21, 47-57. 
Javier San Julián Solana

University of Oviedo

\section{On the Categorial Ambivalence of un montón and Other Similar Quantifiers}

Keywords: un montón/porrón, una barbaridad/bestialidad/burrada/brutalidad, quantifying/quantifier nouns, adverbial phrases, Spanish.

Owing to their ability to express indefinite (superlative) quantification, units like montón, porrón or barbaridad ( bestialidad burrada $\sim$ brutalidad) are often included among quantifying nouns. But along with a series of clearly nominal features, they have other features which are typical of adverbs. The aim of this paper is precisely to provide a reasonable explanation for this categorial hybridism. Applying the theoretical and methodological principles of the Functional Grammar of Spanish, we try to demonstrate that they are not "amphibious" units. On the contrary, we argue that, from a synchronic point of view, two sets of signs should be distinguished, which are functionally and lexically different but have "clonal" signifiers: a) nouns -with designative meaningmontón/es, porrón/es, barbaridad/es, and b) adverbial phrases un montón, un porrón, una barbaridad, which are pure quantifiers, according to their lexeme. 
Javier San Julián Solana

Univerza v Oviedu

\section{O dvoumnosti kategorije un montón in drugih sorodnih količinskih izrazih}

Ključne besede: un montón/porrón, una barbaridad/bestialidad/burrada/ brutalidad, skupni samostalniki, prislovne zveze, španščina

Izrazi montón, porrón in barbaridad (bestialidad/burrada/brutalidad) se pogosto uvrščajo med skupna imena, saj lahko izražajo neopredeljene količine presežne vrednosti. Kljub številnim nespornim samostalniškim značilnostim pa imajo omenjene prvine tudi druge lastnosti, značilne za prislove. Namen prispevka je smiselno utemeljiti in pojasniti to dozdevno kategorično prehajanje ter $\mathrm{s}$ teoretsko-metodološkimi načeli funkcionalne slovnice španščine pokazati, da za omenjene prvine ni značilna protislovna »dvojnost«, temveč da je mogoče v omenjenih pojavih ločiti različne besedne in funkcijske označevalce, ki pa jih, po drugi strani, združuje »istoveten« označevalec: $a$ ) samostalnike, ki označujejo skupna imena: montón/es, barbaridad/es in porrón/es, in b) prave količinske prislovne zveze: un montón, una barbaridad in un porrón. 